\title{
Anaesthetic Management of a Morbidly Obese Parturient for Elective Caesarean Section
}

\author{
Pradhan R, Shrestha S, Gurung T, Shrestha AB, Sharma KR \\ Department of Anaesthesiology Paropakar Maternity and Women's Hospital, Kathmandu, Nepal
}

Received: January 20, 2015 ; Accepted: August 15, 2015

Anaesthesia for an obese parturient poses a challenge to anaesthesiologists. Here we report a case of 27 years obese primigravidae at 40 weeks of gestation with gestational hypertension who underwent elective cesarean section under combined spinal epidural anaesthesia. Her intraoperative and postoperative periods were uneventful.

Keywords: anaesthesia; pregnancy; obesity.

\section{INTRODUCTION}

Obesity has been a global health problem. Perinatal and maternal morbidity is known to be higher in obese population. Obese women are more likely to require anaesthesia during childbirth, as they are more likely to plan for elective caesarean section. ${ }^{1}$ The most recent Confidential Enquiry into Maternal and Child Health (CEMACH) from 2003-2005, highlights obesity as a factor in four of the eight anaesthesia related maternal death. ${ }^{2}$ Obesity exaggerates the anaesthesia related difficulties associated with the physiological changes of pregnancy. The morbidly obese parturient is a significant challenge to the anaesthesiologists. Here we report a case of a morbidly obese parturient that underwent elective caesarean section under combined spinal epidural anaesthesia.

\section{CASE}

A 27 years primigravidae at 40 weeks of gestation with gestational hypertension was scheduled for elective caesarean section. She weighed $127 \mathrm{~kg}$ and height was $152 \mathrm{~cm}$. Thus her body mass index (BMI) was $55 \mathrm{Kg} / \mathrm{m} 2$. She was a booked case with uneventful antenatal checkup. She was an extremely obese term parturient so elective caesarean section was planned. During preanaesthetic checkup, she denied of any medical and surgical problems except that she was diagnosed as gestational hypertension after admission and was under tablet Nifedipine. She had no history of dyspnea, obstructive sleep apnea, diabetes mellitus,

\section{CORRESPONDENCE}

Dr Ritu Pradhan

Department of Anaesthesiology, Paropakar Maternity and

Women's Hospital, Kathmandu, Nepal

Email: ritu_pn@yahoo.com

Phone: +977-9841348757 thyroid dysfunction and drug allergy. She had no past anaesthesia exposure. On examination, her general condition was fair except for mild pedal oedema. Her vitals were: pulse 80 beats per minute and regular, blood pressure $140 / 90 \mathrm{~mm} \mathrm{Hg}$, respiratory rate $20 / \mathrm{min}$ and oxygen saturation $94 \%$ in room air in supine position. On auscultation of chest, there was bilateral equal air entry with no added sounds. Both the heart sounds were audible without murmur. Airway examination revealed Mallampatii grade II, short neck, thyromental distance of $3 \mathrm{~cm}$, adequate mouth opening and normal temporomandibular joint. Peripheral venous accesses and palpation of spine landmarks were difficult due to obesity.

Her preoperative haemoglobin was $10.8 \mathrm{gm} / \mathrm{dl}$. Blood glucose, coagulation profile, renal and liver function tests were within normal limits. A 12 leads ECG showed sinus tachycardia with heart rate of 106 beats per minute. Thus, preoperative assessment revealed her as ASA III. She was kept nil per oral from midnight. High-risk consent was obtained. Elective caesarean section was planned under combined spinal epidural anaesthesia. On the day of surgery, intravenous access was opened with difficulty in left arm with $18 \mathrm{G}$ cannula. She was premedicated with inj. Metoclopramide $10 \mathrm{mg}$ and Ranitidine $50 \mathrm{mg}$. Preloading was done with $1000 \mathrm{ml}$ of Ringer's lactate. Due to unavailability of adequate size sphygmomanometer cuff, continuous arterial pressure monitoring was done via right radial artery cannulation. Her arterial blood gas analysis was within normal limit. The other monitors used were ECG, noninvasive blood pressure in left forearm, oxygen saturation and temperature. The landmark (iliac crest) to identify the intervertebral 
space was not palpable due to obesity. Ultrasound guided intervertebral space was marked. Under all aseptic precautions, epidural Touhy needle $9 \mathrm{~cm}$ was inserted under local anaesthesia in L4-5 space. Loss of resistance was felt at $7 \mathrm{~cm}$. 27G spinal needle of combined spinal epidural set was inserted via Touhy needle for dural puncture but there was no flow of CSF. The needle was taken out and the epidural catheter was fixed at $12 \mathrm{~cm}$. Test dose was given with $3 \mathrm{ml}$ of $2 \%$ xylocaine with adrenaline (1:200000). Subarachnoid block was given with $1.6 \mathrm{ml}$ of $0.5 \%$ Bupivacaine heavy and fentanyl $20 \mathrm{mcg}(0.4 \mathrm{ml})$ in L3-4 space with 26 G Quincke needle. Patient was kept in supine position with 15 degree left lateral tilt.

The level of sensory block obtained was T4. Oxygen was given via nasal prong at 2 litres per minute. Two episodes of hypotension were recorded during intraoperative period, which were managed with intravenous fluid and two bolus doses of $6 \mathrm{mg}$ mephentermine. The surgery was completed within one hour and the outcome was a single live male baby with Apgar score of 6/10 and 8/10 at 1 and 5 minutes respectively. She was transferred to MICU for observation. Postoperative pain management was successfully done with continuous epidural analgesia and paracetamol $1 \mathrm{gm}$ intravenous infusion 6 hourly. Plain Bupivacaine 0.1\% with fentanyl 2 $\mathrm{mcg} / \mathrm{ml}$ was infused at $6 \mathrm{ml}$ per hour. For deep vein thrombosis prophylaxis, TED stocking was used immediately after surgery and low molecular weight Heparin $40 \mathrm{mg}$ subcutaneous OD was started on the 2nd postoperative day after removal of the epidural catheter. Her postoperative course was uneventful.

\section{COMMENT}

Obesity can be defined as condition in which body fat is in excess beyond a point incompatible with the physical and mental health or as a metabolic disorder that is primarily induced and sustained by an over consumption or underutilization of caloric substrate. ${ }^{3}$ Obesity is defined as Body Mass Index $>30 \mathrm{~kg} / \mathrm{m} 2$ and Morbid Obesity is defined as Body Mass Index $>40 \mathrm{~kg} / \mathrm{m} 2$ or Body Mass Index $>35 \mathrm{~kg} / \mathrm{m} 2$ with obesity related co-morbidity. Our patient had BMI of $55 \mathrm{~kg} / \mathrm{m} 2$. Hence this was a case of morbid obesity. According to WHO classification she is class III obese with very severely increased health associated risks. ${ }^{4}$ Fortunately she had no associated comorbidities. The physiological and anatomical changes caused by both obesity and pregnancy increase the potential risk of an anticipated difficult airway, impossible mask ventilation and rapid desaturation during the apneic phase during anaesthesia.

In our case there was anticipated difficult intubation due to short neck and obesity. So we avoided general anaesthesia. She had no history of obstructive sleep apnea. Preoperative arterial blood gas was within normal limit which ruled out obesity hypoventilation related hypoxia, hypercarbia and acidosis. Definitely due to gravid uterus and obesity, there was decreased functional residual capacity. In this case also, supplemental oxygen was given throughout the intraoperative period. Idenfication of landmarks like iliac crest and midline in back for spinal and epidural blocks are also difficult in obese patients due to subcutaneous fat. Ultrasound guided landmark identification is helpful in this type of patients. ${ }^{5}$

Hypertension, cardiac ischaemia, diabetes mellitus and dyslipidaemia are more common in obesity. Endothelial dysfunction, a consequence of insulin resistance and dyslipidaemias, may predispose these patients to pregnancy induced hypertension. ${ }^{6,7}$ Hence cardiologist should be involved preoperatively in symptomatic morbidly obese parturient to evaluate and optimize the patient if required. In this case she had no other comorbidities except gestational hypertension. She had no history of cardiac problems and her metabolic equivalents (METS) was more than four. The supine hypotension syndrome associated with pregnancy can be greatly exaggerated because the large panniculus adds to the uterine compression of the vasculature. There are case reports of sudden death in morbidly obese pregnant patients on assuming the supine position. ${ }^{8}$ So adequate preloading and left lateral tilt with left uterine displacement was also done in our case. Term parturient is always at risk of aspiration due to decreased tone of upper oesophageal sphincter. Adding to this prevalence and severity of gastric reflux are increased in the morbidly obese leading to an increased risk of aspiration during anesthesia. ${ }^{9}$ In this case ranitidine and metoclopramide were given for the premedication.

Obese patients are at risk of thromboembolic complications. Prophylaxis for deep vein thrombosis and mobilization must started early in postoperatively. Low molecular weight heparin according to body weight has been suggested. ${ }^{10}$ 
There are case reports of cesarean section done under spinal and epidural anaesthesia for the obese parturients. ${ }^{11,12}$ Lanny ${ }^{11}$ reported a case of continuous spinal anesthesia for cesarean section for a morbidly obese parturient having history of previous three caesarean sections. Continuous spinal anaesthesia was chosen in this case as the surgical procedure was likely to be long and difficult and the hazards associated with tracheal intubation in morbidly obese parturient were to be avoided. They avoided epidural block with the concern regarding chances of inadequate block. The decision to implement the continuous spinal anesthesia rather than single shot spinal was the concern about encountering a receding spinal level prior to completion of surgery. In our case, we had no such complication. The possibility of conversion to general anaesthesia should be in mind of the anaesthesiologist attending the obese parturient. There should be back up and the preparation for the difficult airway management.

Caesarean section under regional anaesthesia is associated with less maternal morbidity and mortality than general anaesthesia due to reduction of pulmonary aspiration and failed intubation when neuroaxial anesthesia is employed. Besides, neuroaxial blocks also reduce the incidence of venous thrombosis and pulmonary embolism. So this case was planned under combined spinal epidural anaesthesia.
Postoperative pain management via epidural catheter can reduce the parental opioid requirements and thus decrease atelectasis and hypoventilation in obese patients. As the anaesthetic and surgical care of the morbidly obese parturient is challenging, early and meticulous multidisciplinary planning involving senior anaesthesiologists, surgeons, nurses and the preparation of special equipments and back up plans are mandatory.

\section{CONCLUSIONS}

Caesarean section in an obese parturient is associated with multiple risk factors due to physiological and anatomical changes of obesity and pregnancy. Meticulous preoperative assessment and preparation is required. Multidisciplinary involvement of anaesthesiologist, obstetrician, neonatologist, cardiologist and other physicians if necessary are required in the perioperative period. Caesarean section of the morbid obese parturient can be successfully conducted under combined spinal epidural anaesthesia.

\section{DISCLOSURE}

The authors report no conflicts of interest in this work. No violation of human rights and safety.

Funding: Nil

\section{REFERENCES}

1. Alanis MC, Goodnight WH, Hill EG, Robinson CJ, Villers MS, Johnson DD. Maternal superobesity (body mass index $\geq 50$ ) and adverse pregnancy outcomes. Acta Obstet Gynecol Scand. 2010;89:924-30.

2. Cooper GM, McClure JH. Anaesthesia chapter from saving mother's lives; reviewing maternal deaths to make pregnancy safe. Br J Anaesth. 2008;100(1):17-22.

3. National Institute of health consensus development conference statement. Health implication in obesity. Ann Int Med. 1985;103:147-51

4. WHO. Obesity: preventing and managing the global epidemic. Report on a WHO consulation, WHO technical report series 894. Geneva: WHO; 2000.

5. Jason L, Santosh P. Ultrasound for obstetric neuraxial anesthetic procedures: Practical and useful? J Obstet Anesth Crit Care. 2015;5(2):49-53

6. Ramsay JE, Ferrell WR, Crawford L, Wallace AM, Greer IA Sattar N. Maternal obesity is associated with dysregulation of metabolic, vascular, and inflammatory pathways. J Clin Endocrinol Metab. 2002;87:4231-37.
7. Wolf M, Kettyle E, Sandler L, Ecker Jl, Roberts J, Thadhani R. Obesity and preeclampsia: the potential role of inflammation. Obstet Gynecol. 2001;98:757-62.

8. Tsueda K, Debrand M, Zeok SS, Wright BD, Griffin WO. Obesity supine death syndrome of two morbidly obese patients. Anesth Analg. 1979;58:345-47.

9. Roberts RB, Shirley MA. Reducing the risk of acid aspiration during cesarean section. Anesth Analg. 1974;53:859-68.

10. Michota F, Merli G. Anticoagulation in special patient populations: are special dosing considerations required? Clev Clin J Med. 2005;72(suppl.1):S37-42.

11. Lanny LC. Continuous spinal anesthesia for cesarean section for a morbidly obese parturient: A case report. AANA J. 2002;70(3):189-92.

12. Hanan ES, Ian K and Thomas S. Anesthetic management of a morbidly obese parturient undergoing cesarean section. Middle East J Anesth. 2011;21(2):289-311. 